\title{
PRODUÇÃO ACADÊMICA DA ÁREA TEMÁTICA MERCADOS FINANCEIRO, DE CRÉDITO E DE CAPITAIS (MFC) DIVULGADA NO ANPCONT DE 2007 A 2016
}

\section{ACADEMIC PRODUCTION OF THE THEMATIC AREA FINANCIAL MARKETS, CREDIT AND CAPITAL (MFC) DISCLOSED AT ANPCONT FROM 2007 TO 2016}

\author{
Henrique Cesar Melo Ribeiro ${ }^{2}$ \\ Doutor em Administração de Empresas pela Universidade Nove de Julho \\ Professor da Universidade Federal do Piauí (UFPI) \\ hcmribeiro@hotmail.com
}

\section{RESUMO}

Objetivo: $\mathrm{O}$ objetivo deste estudo foi investigar o perfil e as características da produção científica dos artigos divulgados na AnpCONT na área temática Mercados Financeiro, de Crédito e de Capitais de 2007 a 2016.

Fundamento: Investigar a produção acadêmica é salutar para qualquer campo do conhecimento, pois propicia um mapeamento do saber estabelecido, permite determinar as temáticas de pesquisa da área, quais são os autores e instituições mais profícuas e as redes de atores.

Método: Utilizaram-se as técnicas de análise bibliométrica e de rede social.

Resultados: Alfredo Sarlo Neto, Bruno Funchal e Márcio André Veras Machado foram os autores mais profícuos. Fucape Business School, Universidade Federal da Paraíba e Universidade Federal do Espírito Santo foram as instituições mais produtivas. Constatou-se uma centralidade de grau e de intermediação nas redes de coautoria e das instituições, influenciando em sua baixa densidade e em sua dispersão. Os temas mais publicados foram: governança corporativa, investimento, informações contábeis, gerenciamento de resultados, auditoria, estrutura de capital, gestão de risco, mercado corporativo, retorno das ações e avaliação de empresas.

Contribuições: Esta investigação conclui de maneira macro, as nuances da área temática mercados financeiro, de crédito e de capitais, à luz do congresso AnpCONT, enfatizando em seu bojo dados e informações contemporâneas, no que se refere a autores, instituições, redes dos atores e temas abordados, contribuindo para um maior e melhor entendimento e compreensão destas variáveis, colaborando posteriormente para seu pleno desenvolvimento, difusão e socialização, influenciando no crescimento das temáticas ora investigadas e, também para o campo do conhecimento Contabilidade.

Palavras-chave: Produção acadêmica. Mercados financeiro, de crédito e de capitais. AnpCONT. Bibliometria. Rede social.

\footnotetext{
1 Artigo recebido em: 15/02/2017. Revisado por pares em: 03/04/2017. Reformulado em: 28/04/2017. Recomendado para publicação em: 21/05/2017 por Dimas Barrêto de Queiroz (Editor Adjunto). Publicado em: 31/08/2017. Organização responsável pelo periódico: UFPB.

${ }^{2}$ Endereço: Avenida São Sebastião, n. 2819. Campus Ministro Reis Velloso. Parnaíba/PI. CEP: 64202-020

DOI: http://dx.doi.org/10.18405/recfin20170305
} 


\section{ABSTRACT}

Objective: The aim of this article was to investigate the profile and characteristics of the scientific production of the articles published in AnpCONT in the Financial Markets, Credit and Capital theme from 2007 to 2016.

Background: Investigating the academic production is convenient for any field of knowledge, since it provides a mapping of established knowledge, allows to determine the research topics of the area, which authors and institutions are most profitable and networks of actors.

Method: Bibliometric and social network analysis techniques were used.

Results: Alfredo Sarlo Neto, Bruno Funchal and Márcio André Veras Machado were the most prolific authors. Fucape Business School, Federal University of Paraíba and Federal University of Espírito Santo were the most productive institutions. It was verified a centrality of extent and of intermediation in the networks of co-authoring and of the institutions, influencing in its low densidad and its dispersion. The most published topics were: corporate governance, investment, accounting information, results management, auditing, capital structure, risk management, corporate market, stock returns and company valuation.

Contributions: This research concludes in a macro form, the nuances of the financial, credit and capital markets area, in the light of the AnpCONT congress, emphasizing in its bulge contemporary data and information, regarding authors, institutions, networks of actors and themes And contributing to a greater and better understanding and comprehension of these variables, contributing later to its full development, diffusion and socialization, influencing the growth of the themes investigated and also to the field of knowledge Accounting.

Keywords: Academic production. Financial, credit, and capital markets. AnpCONT. Bibliometrics Social network.

\section{INTRODUÇÃO}

A produção científica influencia as avaliações de pesquisadores e Instituições de Ensino Superior (IESs), sobretudo nos programas de pós-graduação stricto sensu (Ferreira \& Falaster, 2016). E a avaliação da produção científica é de basilar importância para se mensurar a qualidade dos estudos científicos (Leite Filho \& Siqueira, 2007), em periódicos (Ribeiro, 2015), como também em congressos (Anzilago \& Melo, 2016, Cosenza, Paula, Laurencel \& Barreto, 2016).

Diante disso, Arboit e Bufrem (2011, p. 207) afirmam que os congressos científicos são considerados meios de comunicação mais informais e, com decorrência, mais ágeis na evidenciação e na troca do saber científico. Diferentemente dos livros e revistas científicas, grande parte da informação é evidenciada oralmente, instigando o debate instantâneo dos pesquisadores interessados na temática. Contudo, antes de se virarem públicos os estudos submetidos ao congresso passam por avaliação robusta do comitê científico, frequentemente constituído por pesquisadores do campo. Esse procedimento de avaliação é parecido ao dos artigos de revistas científicas, apesar da publicação nestas revistas ser, em geral, mais estimada. Os congressos científicos admitem também o contato informal entre os autores que atuam no mesmo campo do conhecimento. Sendo assim, agrupam pesquisadores com interesse comum, excitam a troca e compartilhamento de conhecimento e a criação de valor acadêmico, mediante novas parcerias ou grupos de estudo, uma vez que a troca de informações e saberes se dá de maneira mais ativa do que os outros meios de comunicação científica, apesar do seu escopo menos formal.

Ressalta-se que na área contábil nacional, nos últimos anos, vem evoluindo a quantidade de eventos científicos norteados para evidenciar a produção acadêmica dos programas de mestrado e doutorado em Ciências Contábeis. Destes, pode-se mencionar o encontro da Associação Nacional de Programas de Pós-Graduação em Ciências Contábeis (AnpCONT ) (Cosenza et al., 2016). 
O Congresso AnpCONT está classificado entre os principais eventos científicos da área de contabilidade do Brasil (Cosenza et al., 2016). Nele se concentram as áreas temáticas: Contabilidade Aplicada ao Setor Público e ao Terceiro Setor (CPT), Controladoria e Contabilidade Gerencial (CCG), Educação e Pesquisa em Contabilidade (EPC), Contabilidade para Usuários Externos (CUE) e Mercados Financeiro, de Crédito e de Capitais (MFC) (AnpCONT, 2017).

Dentre estas áreas temáticas, realçam-se a MFC que compreende pesquisas voltadas para os aspectos conceituais e/ou empíricos dos mercados financeiro, de crédito e de capitais, bem como a aplicação de recursos à luz dos desempenhos organizacionais passados e/ou os projetados. A citada área temática desdobra-se, sobretudo, nos seguintes focos: auditoria, finanças corporativas, valuation, gestão de riscos, métodos quantitativos aplicados à contabilidade (AnpCONT, 2017).

Encontraram-se na literatura acadêmica brasileira, trabalhos analisando somente as publicações da AnpCONT (Dallabona et al., 2011; Cosenza et al., 2016; Anzilago \& Melo, 2016). Contudo, somente o estudo dos autores Amaral, Santana, Sales e Araujo Neto (2014) versando sobre a temática MFC, foi identificado na literatura científica nacional, Amaral et al. (2014) analisaram por meio do método bibliométrico o perfil da produção científica em Mercado Financeiro e de Capitais a partir dos artigos publicados no Congresso USP de Controladoria e Contabilidade e no Congresso ANPCONT entre 2007 e 2011. Constataram que a área temática MFC nestes dois congressos ainda está concentrada na mão de poucos autores e a maioria dos pesquisadores ainda apresenta uma única participação em ambos eventos.

Sabendo que a produção científica na área contábil cresceu nos últimos anos e paralelamente os estudos que focam as técnicas de análise bibliométrica em contabilidade. e que, a análise da área temática Mercado Financeiro de Crédito e de Capitais, merece atenção dos estudos bibliométricos (Amaral et al., 2014). Este estudo é norteado pela seguinte questão de pesquisa: Qual é o perfil e as características da produção científica dos artigos divulgados na AnpCONT na área temática Mercados Financeiro, de Crédito e de Capitais de 2007 a 2016? E o objetivo que ampara tal questão é: investigar o perfil e as características da produção científica dos artigos divulgados na AnpCONT na área temática Mercados Financeiro, de Crédito e de Capitais de 2007 a 2016.

Justifica-se fazer este estudo, pois: (i) irá abordar uma temporalidade de 10 anos da produção cientifica da área temática Mercados Financeiro, de Crédito e de Capitais; (ii) irá somente focar na área temática Mercados Financeiro, de Crédito e de Capitais da AnpCONT; (iii) existe poucos estudos sobre a área temática Mercados Financeiro, de Crédito e de Capitais na literatura acadêmica nacional; e (iv) possibilitará agregar valor acadêmico no que se refere a área temática Mercados Financeiro, de Crédito e de Capitais, e consequentemente ao campo do conhecimento Contabilidade na literatura acadêmica brasileira.

Diante disso, esta investigação vem contribuir para desenvolver, difundir, disseminar e socializar a produção acadêmica (Pimenta \& Fama, 2014), da temática Mercados Financeiro, de Crédito e de Capitais no contexto científico literário contábil nacional, proporcionando assim um maior entendimento e robusta compreensão da importância e do realce que a referida área do saber tem para o meio acadêmico contábil. Este estudo contribui também para fazer com que esta área temática, que no seu tocante é recente na contabilidade, sobretudo, nos aspectos de sua produção acadêmica, seja fomentada, impactando com isso em seu aperfeiçoamento, alargamento e posterior maturidade na academia.

Esta pesquisa está dividida em cinco seções. A primeira seção aborda a Introdução, com a questão, objetivo, justificativa, contribuição da pesquisa. O referencial teórico é a segunda seção. Os procedimentos metodológicos vêm logo a seguir. As análises e discussões dos resultados são evidenciadas na seção quatro. E, por fim, na seção cinco, têm as considerações finais, norteadas pelas conclusões, contribuições, limitações e sugestões para estudos futuros. 


\section{FUNDAMENTAÇÃO TEÓRICA}

Esta seção abordará a temática Mercados Financeiro, de Crédito e de Capitais, focando em conceitos, importância, e suas respectivas produções cientificas já publicadas na literatura científica brasileira.

\subsection{Mercados financeiro, de crédito e de capitais: conceitos e produção científica}

O mercado financeiro é uma entidade que norteia a economia (Krugman, 2010), e que reúne vários stakeholders (Matsuda \& Donadone, 2015) que se preocupam em captar ou ceder recursos financeiros por motivos e para fins diversos (Santos \& Santos, 2005). Ou seja, o mercado financeiro dá condições para negociação entre grupos de stakeholders com recursos financeiros para investir e grupos que precisam de captação de recursos (Marques, 2010), criando condições de liquidez no mercado (Malacrida \& Yamamoto, 2006).

Existe de um lado um grupo de poupadores, cuja renda lhes admite atender suas necessidades de consumo imediato e, ainda, economizar parte para aplicar no mercado. Existem também aqueles que necessitam de recursos adicionais para fazer frente a suas necessidades imediatas, sejam elas para consumo ou para investimentos (Santos \& Santos, 2005). E há um terceiro grupo de stakeholders: os intermediários, ou seja, instituições responsáveis por criar o mercado, isto é, agrupar os vários tomadores e investidores e propiciar a realização de negócios, pelos quais auferem uma comissão (Santos \& Santos, 2005).

Diante disso, entende-se que o mercado financeiro é voltado para a transferência de recursos entre os investidores e os poupadores (Herling, Moritz, Lima \& Pereira, 2014), sendo assim considerado fator chave e primordial no desenvolvimento de um país, o que faz deste tema um atraente tópico de estudo e, ao mesmo tempo, um desafio para a ciência contemporânea (Crepaldi, Ferreira \& Rodrigues, 2012). De maneira geral, o mercado financeiro é dividido em duas categorias: mercado de crédito e mercado de capitais (Malacrida \& Yamamoto, 2006).

O mercado de crédito é composto por instituições e instrumentos financeiros (Malacrida \& Yamamoto, 2006) dedicados a permitir operações de curto ou médio prazo (Chaddad \& Lazzarini, 2003), para agentes deficitários (CVM, 2017). E o mercado de capitais composto por instituições e instrumentos financeiros designados a liberar operações de médio ou longo prazo (Kimura, 2003; Malacrida \& Yamamoto, 2006), por meio das operações de compra e de venda de títulos e valores mobiliários efetuados entre empresas, investidores e intermediários (CVM, 2017).

É salutar informar, que, o desenvolvimento do mercado de capitais é um dos fatores primordiais para o crescimento econômico de uma nação, e seu consequente fortalecimento está alicerçado nos princípios das boas práticas de governança corporativa (Ferri \& Soares, 2009). Diante do exposto, ressalta-se que a governança corporativa é importante, pois, fornece e divulga ao mercado de capitais informações relevantes para a tomada de decisões (Almeida, Santos, Ferreira \& Torres, 2010). Realça-se também que, além destas informações sobre a saúde financeira e o desempenho das organizações, os investidores também necessitam ter o conhecimento de como essas empresas estão sendo administradas, e as boas práticas de governança corporativa (Almeida, Santos, Ferreira \& Torres, 2010), como estratégia (Gonçalves et al., 2012) dão legitimidade nisso (Martins \& Rodrigues, 2005).

De maneira geral, salienta-se que o estudo de Finanças é preponderante para se entender e compreender como os empreendimentos são avaliados e financiados (Fonseca \& Utrero, 2017), seus recursos financeiros e riscos são geridos (Dionne, 2013), e como o mercado financeiro atua na intermediação das transações que o viabilizam (Leal, Almeida \& Bortolon, 2013). Neste sentido, observase que assuntos relacionados a finanças (Rocha et al., 2014), como por exemplo, o mercado financeiro, mercado de capitais (Herling et al., 2014), vêm se desenvolvendo e crescendo nos últimos anos no Brasil (Rocha et al., 2014). 
Neste âmbito, evidenciam-se a seguir, estudos sobre a produção científica relacionada a área do conhecimento finanças e consequentemente às temáticas: mercado financeiro, mercado de crédito, e/ou mercado de capitais e afins publicados em periódicos e/ou em congressos científicos da área de contabilidade e/ou afins nos últimos anos, para proporcionar e viabilizar futuras e possíveis discussões na seção correspondente nesta investigação.

Leal, Oliveira e Soluri (2003) traçaram um perfil da pesquisa em finanças no Brasil nas últimas décadas. Constataram que a produtividade dos autores nacionais está mais concentrada em poucos indivíduos e é mais baixa do que o sugerido pela teoria bibliométrica. Mais de $70 \%$ dos autores publicou apenas um artigo. Verificaram que a maioria dos artigos é de autores afiliados à UFRJ, PUC/RJ e USP.

Vieira e Pereira (2009) mapearam os trabalhos realizados no Brasil a respeito do tema finanças comportamentais de 2001 a 2007. Identificaram que a produção científica sobre finanças comportamentais está concentrada no Encontro da Associação Nacional de Pós-Graduação e Pesquisa em Administração (ENANPAD), com 70\% das publicações. Tal fato mostra que o crescimento da publicação em eventos não foi acompanhado pelas revistas, geralmente associadas a um maior rigor metodológico, o que sugere uma necessidade de melhoria da qualidade da publicação na área.

Catapan, Scherer e Espejo (2010) analisaram as tendências temáticas e metodológicas dos artigos sobre informações contábeis no mercado de capitais publicados em periódicos entre os anos de 2000 e 2009. Os resultados da maioria das pesquisas apontam uma relação positiva entre divulgação contábil e valores de títulos negociados.

Diehl, Macagnan, Zanini e Wickboldt (2010) verificaram as metodologias aplicadas em artigos de finanças sobre "dividendos", publicados nos principais periódicos brasileiros (qualificação pelo Qualis/CAPES acima de B2), além de outras analises sobre características dos mesmos. Constataram que existe uma oportunidade de pesquisa no tema, frente a baixa produção encontrada em relação ao total de trabalhos (menos de 1\%). Até mesmo os periódicos especializados em finanças e contabilidade, como: RBFin e RCeFinUSP apresentam percentuais abaixo de $5 \%$ do total de trabalhos dedicados ao tema dividendos.

Leal, Almeida e Bortolon (2013) traçaram um perfil dos artigos de Finanças publicados em periódicos brasileiros selecionados no período entre 2000 e 2010. Verificaram que as áreas temáticas mais comuns, finanças corporativas e gestão de investimentos, refletem a abundância de dados de empresas com ações em bolsa, negligenciando as demais. A produtividade é concentrada em poucos indivíduos no Sudeste e mais baixa do que o previsto pela teoria bibliométrica. A grande maioria dos autores publicou apenas um artigo e apenas $5 \%$ publicaram cinco ou mais.

Amaral et al. (2014) analisar as características gerais da produção científica, bem como o perfil dos autores na área temática de Mercados Financeiros de Crédito e de Capitais nos Congresso USP e AnpCONT. Os resultados achados pelos autores foram no que tange ao evento AnpCONT foram: predominância de artigos publicados em parceria; a região Sudeste se destaca na produção dos artigos; a Fucape Business School é a IESs mais profícua; e Alfredo Sarlo Neto foi o acadêmico mais prolífero.

Cordeiro et al. (2014) analisaram se há diferenças, em termos de sofisticação e rigor, nas técnicas estatísticas utilizadas por artigos de finanças, publicados em periódicos qualificados pela CAPES, no triênio 2007-2009. Os resultados obtidos pelos autores sugerem que, quanto maior o nível de classificação do estrato, maior é a sofisticação das técnicas estatísticas empregadas nos artigos. Todavia, com relação ao rigor na aplicação das técnicas, verificou-se não haver diferenças significativas entre um estrato e outro.

Faria, Andrade e Gonçalves (2015) descreveram a situação da produção científica no campo de finanças, por meio de dados levantados a partir dos artigos publicados em periódicos nacionais. 
Os pesquisadores constataram que os temas: governança; fusão e aquisição; estrutura de propriedade, investimento e apreçamento de ativos, estrutura de capital; dividendos e capital de giro e gestão de riscos e derivativos foram os mais abordados.

Herling, Moritz, Soares e Lima (2015) buscaram entender como estão as publicações na área de administração financeira nas revistas classificadas de alto impacto, de acordo com o último Qualis publicado pela Capes no ano de 2012. Verificaram que, entre 2010 até 2012, existe uma concentração maior de pesquisas nas subáreas Finanças de Curto Prazo, Finanças de Longo Prazo e Mercados e Instituições Financeiras; que os pesquisadores com maior produtividade são da Universidade Presbiteriana Mackenzie e da Fundação Getúlio Vargas (EAESP/FGV); e que as revistas RAUSP e RAE apresentam a maior quantidade de artigos publicados sobre finanças.

Ribeiro (2017) investigou o perfil e as particularidades da produção acadêmica do tema gestão de riscos divulgada nas revistas científicas disponibilizadas na Base Atena de 2000 a 2015. Constatou que a Universidade de São Paulo (USP) e a Universidade de Brasília (UnB), foram as IESs que se destacaram na produção acadêmica sobre gestão de riscos e também como as mais centrais. Sobre as redes sociais, foi observado que, tanto a rede de coautoria como a rede das IESs têm baixa densidade, influenciando em suas respectivas dispersões.

Analisando os estudos sobre a exploração da produção científica de temáticas relacionadas a área financeira, observa-se que nenhum destes, exceto a pesquisa de Amaral et al. (2014), focou de maneira conjunta nos temas, mercado financeiro, mercado de crédito e mercado de capitais. No que se refere ao estudo de Amaral et al. (2014), este focou a temática mercados financeiro, de crédito e de capitais, porém, de 2007 a 2011, ou seja, cinco anos; e não apenas no congresso AnpCONT, mas também no congresso da USP. Esta investigação é contemporânea, além de que, mapeia uma década de publicações na mencionada área somente no evento científico AnpCONT.

Com isso, reitera-se e reforça-se aqui a justificativa e a importância deste atual estudo para o alargamento do campo do saber das finanças, sobretudo, analisando as temáticas mercados financeiro, de crédito e de capitais, mesmo, sob a ótica do congresso AnpCONT, contudo, por ser considerado um dos principais eventos científicos da área de Contabilidade, se faz relevante, representável e porque não dizer, legitimado no panorama científico brasileiro, viabilizando assim a atual investigação, contribuindo para influenciar no desenvolvimento, fomento, disseminação e socialização destas temáticas na academia.

\section{PROCEDIMENTOS METODOLÓGICOS}

O objetivo deste estudo foi investigar o perfil e as características da produção científica dos artigos divulgados na AnpCONT na área temática Mercados Financeiro, de Crédito e de Capitais de 2007 a 2016. Para tanto, utilizou-se as técnicas de análise bibliométrica e de rede social.

A bibliometria é uma técnica de análise em constante desenvolvimento, aperfeiçoada pelas Ciências da Informação, que utiliza análises quantitativa, estatística e de visualização de dados não somente para investigar a estrutura de um campo do conhecimento científico, mas também como uma ferramenta primária para a análise da conduta dos autores em suas decisões na construção e na evidenciação desse saber científico (Caldas \& Tinoco, 2004). Ou seja, a bibliometria realiza uma investigação apurada dos desenvolvimentos dos mais variados campos do conhecimento científico, alicerçada por indicadores bibliométricos que incluem, por exemplo: artigos publicados, autores, instituições (Ruas \& Pereira, 2014).

Ressalva-se que as principais leis bibliométricas são: Lei de Bradford, (foca na produtividade de periódicos), Lei de Lotka (enfatiza a produtividade científica de autores) e Leis de Zipf (versa sobre a frequência de palavras) (Guedes \& Santos, 2013). Em suma, A Lei de Lotka, ou Lei do Quadrado Inverso, mensura a produtividade dos autores por meio de um modelo de distribuição de tamanho- 
freqüência dos diversos autores em um conjunto de textos. A Lei de Bradford, ou Lei de Dispersão, admite, por meio da aferição da produtividade dos periódicos, constituir o núcleo e os campos de dispersão sobre um determinado tema em um mesmo conjunto de periódicos cientificos. Já a Lei de Zipf, ou Lei do Mínimo Esforço, incide em calcular a freqüência do surgimento das palavras em vários documentos, criando uma lista ordenada de termos de uma determinada temática (Cardoso, Mendonça Neto, Riccio \& Sakata, 2005). Para este estudo, em decorrência da questão de pesquisa e do objetivo a serem respondido e encontrado respectivamente, será usada somente a Lei de Lotka.

Contudo, é importante ressaltar que, ao usar de maneira conjunta as técnicas de análise bibliométrica, com as análises de redes sociais (Ribeiro, 2014), permite um maior entendimento e compreensão da estrutura, das características e do comportamento das relações entre os autores, instituições e temas (Francisco, 2011). Portanto, uma avaliação da cooperação entre os pesquisadores dos artigos amplia os estudos bibliométricos para as manifestações de colaboração intelectual na pesquisa científica. Diante disso, evidencia-se que o uso de técnicas de análise de redes sociais vem sendo cada vez mais utilizada e explorada em estudos científicos nacionais (Francisco, 2011).

Neste contexto, Fialho (2014, p. 12) afirma que a análise de redes sociais foca nas relações entre vários elementos, especificamente, indivíduos, grupos, instituições, etc., sendo que, com cada tipo de conexão se pode arquitetar uma rede social distinta. Uma das principais diferenças das análises das redes sociais clássicas que elucidam a conduta dos atores em função, por exemplo, da classe social ou profissão, é que a análise de redes sociais se centra nas afinidades e atributos desses elementos. Ou seja, que a matriz que suporta a análise de redes sociais é a estrutura das analogias que assumem um carácter explicativo, mais expressivo que os predicados pessoais dos elementos que compõem um determinado sistema.

Os procedimentos vinculados à análise de redes sociais podem ser agrupados em atributos estruturais, como, por exemplo, as medidas de densidade, e de centralidade (Rossoni, Hocayen-daSilva \& Ferreira Júnior, 2008). A densidade é a medida de intensidade da interação dos atores da rede social, sendo que com sua aferição contribui para a formulação de conjecturas sobre as informações e o conhecimento científico que circundam pela rede social (Mello, Crubellate \& Rossoni, 2010).

Já a centralidade é a medida de quão acessível, importante e relevante um determinado ator é/está para os demais atores da rede social, dependendo do padrão de distribuição, ou da forma como os vários atores estão conectados. A centralidade, além de aferir a acessibilidade, importância e relevância de um ator, calcula o número de caminhos de comunicação que passam por ele. Quanto maior for o número de ligações entre os atores de uma rede social, menor a probabilidade de atores centrais deterem o controle sobre o fluxo de informações e consequentemente do conhecimento científico (Régis, Bastos \& Dias, 2007).

Três medidas são mais frequentemente usadas para se avaliar a centralidade, são elas: centralidade de grau (degree); centralidade de intermediação (betweenness) e centralidade de proximidade (closeness) (Rossoni \& Guarido Filho, 2007). A centralidade de grau é conseguida a partir do número de vínculos diretos que um ator possui; e a medida de centralidade de intermediação pondera se um ator ostenta, ou não, posição de intermediador (Cruz, Espejo, Costa \& Almeida, 2011).

\subsection{Procedimentos de coleta de dados}

Foi feita uma coleta de dados em artigos evidenciados no período de 2007 a 2016, o que corresponde a um levantamento longitudinal de 10 anos. Os dados foram coletados da Associação Nacional de Programas de Pós-Graduação em Ciências Contábeis (http://www.anpcont.org.br/congressos-anpcont). Os artigos envolvidos neste estudo foram especificamente da área temática mercados financeiro, de crédito e de capitais. Este processo consentiu identificar 156 estudos evidenciados no período 2007-2016. 


\subsection{Procedimentos de análise de dados}

Foi realizada a análise dos dados mediante os seguintes indicadores: (I) autores; (II) rede de coautoria; (III) IESs; (IV) rede social das IESs; e (V) temas abordados. Estes indicadores foram calculados e capturadas, utilizando os softwares UCINET 6 for Windows e Microsoft Excel 2007. Ressalva-se que estes softwares foram também usados para aferir e elaborar as Figuras e a Tabela evidenciada neste estudo.

No que tange a criação da Tabela deste estudo, a identificação dos 57 temas manifestados nela, foi feita por meio de embasamento e norte das informações contempladas no site da AnpCONT, em especial no que se refere ao seu foco e escopo. Em relação as Figuras, todas tiveram origem em seus dados no Microsoft Excel 2007, entretanto, as figuras de redes foram montadas no UCINET 6 for Windows e criadas no NetDraw.

É importante ressalvar que presentemente existem determinados programas para computadores que amparam o uso da análise de redes. Assim, a alternativa de um software a ser usado para assessorar no mapeamento de uma rede é uma preferência pessoal. Sob esta ótica, versa-se que o UCINET é um dos melhores entre os disponíveis (Albuquerque Filho \& Machado-da-Silva, 2009), justificando assim, a utilização do referido software neste trabalho.

\section{ANÁLISE E DISCUSSÃO DOS RESULTADOS}

Esta seção aborda a análise e discussão dos resultados dos 156 artigos identificados sobre a temática mercados financeiro, de crédito e de capitais divulgados no AnpCONT de 2007 a 2016.

\subsection{Autores}

A Figura 1 evidencia os 293 autores identificados neste estudo, colocando em ênfase os 13 mais profícuos.

Figura 1: Autores

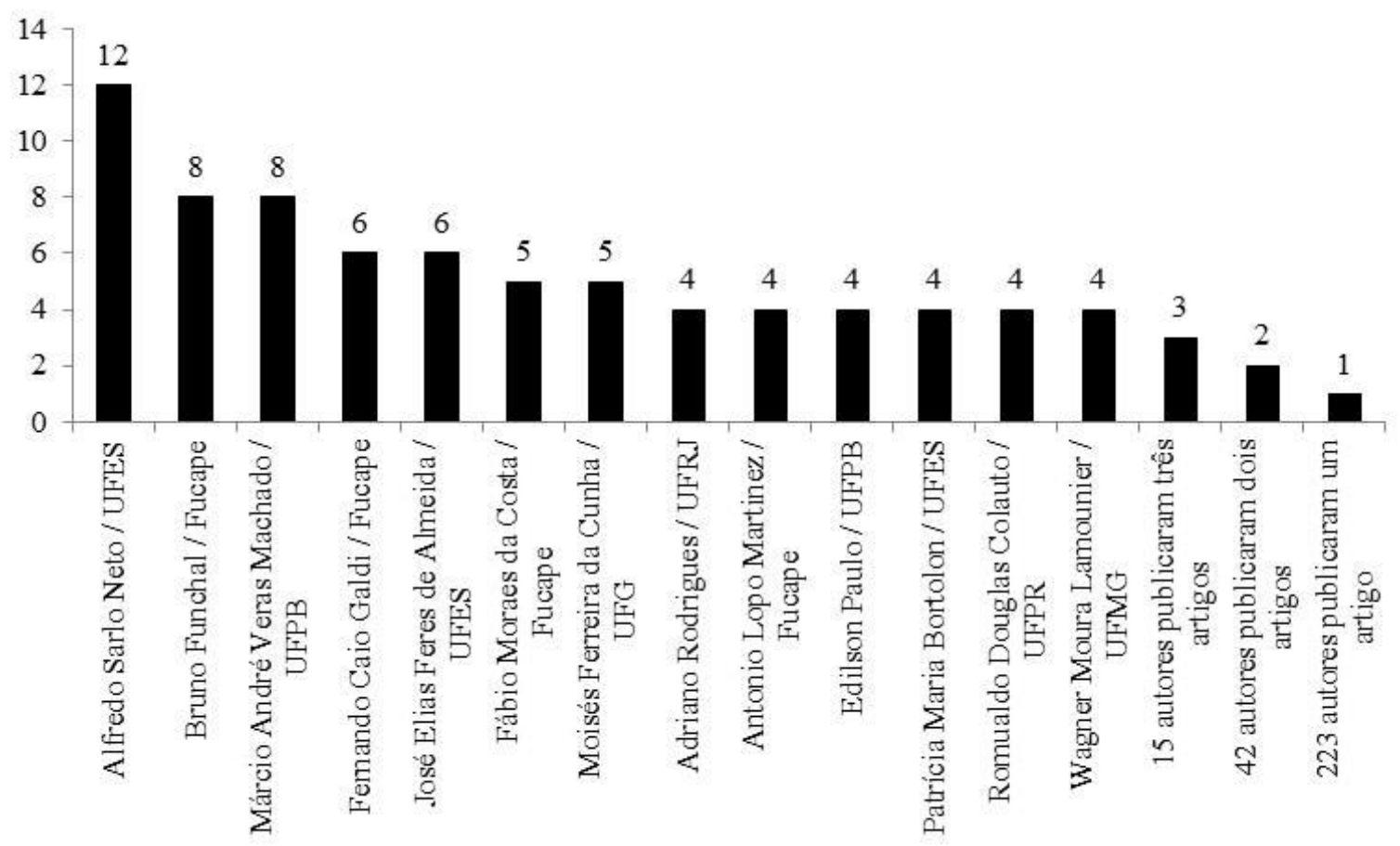

Fonte: Dados da pesquisa

O autor Alfredo Sarlo Neto se destacou como o mais prolífero neste estudo, ao publicar 12 artigos divulgados na área temática mercados financeiro, de crédito e de capitais. Logo em seguida 
aparecem os pesquisadores: Bruno Funchal e Márcio André Veras Machado, ambos com oito publicações. Com seis trabalhos evidenciados tem os pesquisadores: Fernando Caio Galdi e José Elias Feres de Almeida. Já os articulistas Fábio Moraes da Costa e Moisés Ferreira da Cunha, publicaram cinco investigações cada. E com quatro surgem os acadêmicos: Adriano Rodrigues, Antonio Lopo Martinez, Edilson Paulo, Patrícia Maria Bortolon, Romualdo Douglas Colauto e Wagner Moura Lamounier. Os achados são corroborados de maneira similar com o estudo dos autores Amaral et al. (2014), sobretudo em relação ao acadêmico mais profícuo, que, tanto neste trabalho, como também na pesquisa de Amaral et al. (2014) é Alfredo Sarlo Neto.

De maneira geral, 13 autores publicaram de quatro a 12 estudos; 57 pesquisadores publicaram de dois a três trabalhos; e a grande maioria, ou seja, 223 acadêmicos divulgaram somente um artigo cada, o que percentualmente equivale a aproximadamente $76 \%$ do montante dos pesquisadores. Tal resultado é confirmado de maneira parecida nos trabalhos que focam na área financeira, são eles: Leal, Oliveira e Soluri (2003), Leal, Almeida e Bortolon (2013) e Ribeiro (2017). Observando ainda a Figura 1, percebe-se que poucos autores publicam muito e que muitos pesquisadores publicam pouco, o que remete a produtividade dos acadêmicos (Ribeiro, 2017), isto é, a Lei de Lotka (Cardoso, Mendonça Neto, Riccio \& Sakata, 2005).

\subsection{Rede de coautoria}

A Figura 2 visualiza a rede de coautoria dos 293 pesquisadores identificados neste trabalho, realçando a centralidade de grau.

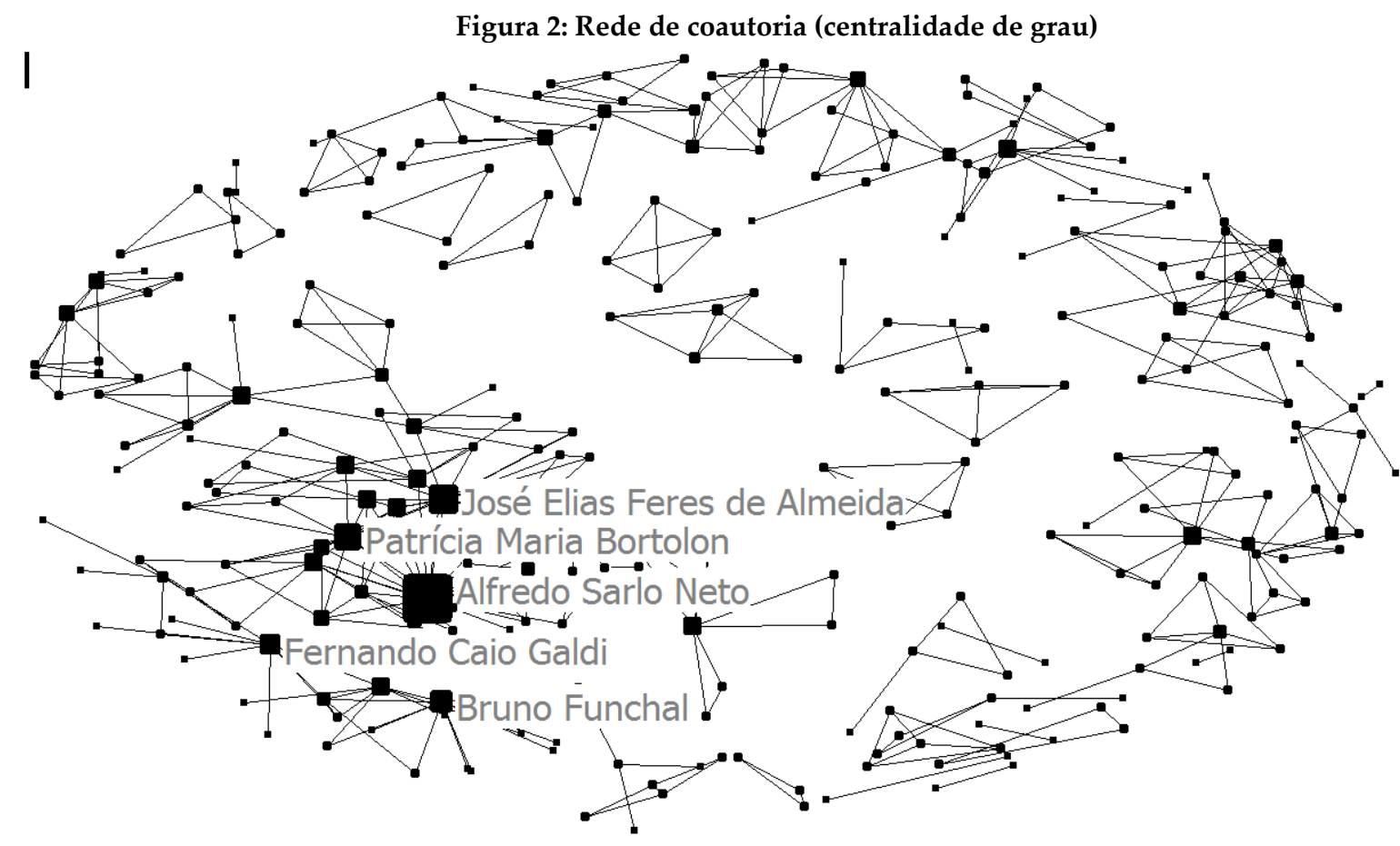

Fonte: Dados da pesquisa

Evidencia-se que a densidade da Figura 2 é de 0.0101, ou seja, somente 1,01\% das interações entre os autores são efetivamente realizada, mostrando que, $98,99 \%$ dos relacionamentos na rede não são realizadas. Tal resultado pode ser em decorrência da quantidade de anos de publicação da área temática objetivo de estudo, impactando na baixa densidade e sua consequente dispersão.

Ainda sobre a Figura 2, têm-se os autores com maior centralidade de grau, são: Alfredo Sarlo Neto, José Elias Feres de Almeida, Patrícia Maria Bortolon, Bruno Funchal e Fernando Caio Galdi. 
Destes, todos aparecem em destaque, neste estudo, como pesquisadores mais profícuos, o que mostra a envergadura, importância e relevância destes para o fomento, difusão e disseminação das informações e conhecimento científico (Cruz et al., 2011), da área temática mercados financeiro, de crédito e de capitais na literatura científica nacional, mediante o congresso científico AnpCONT.

Já a Figura 3 é similar a Figura 2, contudo, coloca em foco a centralidade de intermediação.

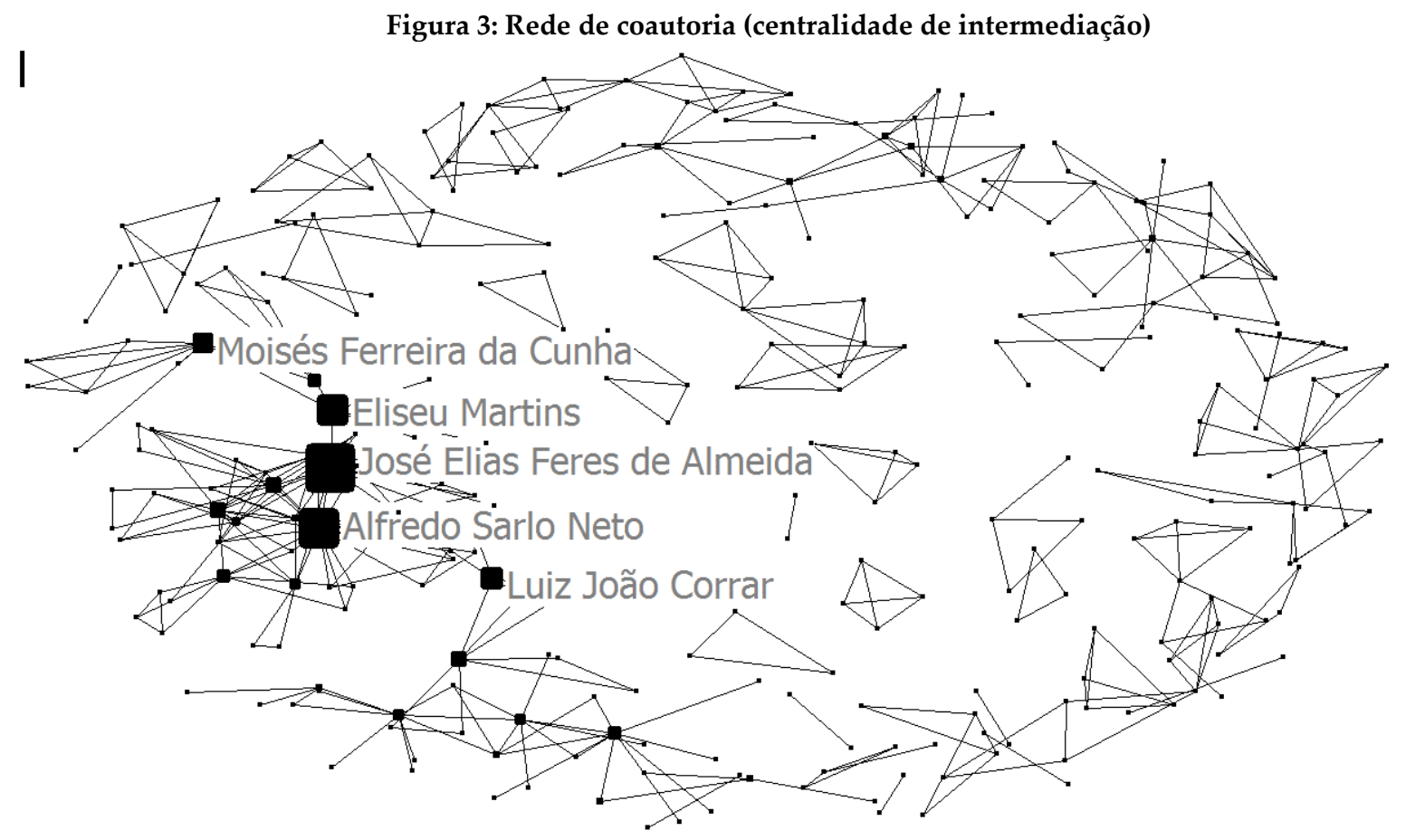

Fonte: Dados da pesquisa

Observando a Figura 3, têm-se José Elias Feres de Almeida, Alfredo Sarlo Neto, Eliseu Martins, Luiz João Corrar e Moisés Ferreira da Cunha como os pesquisadores com maior centralidade de intermediação. Tal achado vislumbra que estes autores ostentam uma posição de intermediador na rede de coautoria (Cruz et al., 2011). Ou seja, intermediando futuras conexões entre autores, otimizando com isso a troca de informações e do saber cientifico, influenciando e agregando valor acadêmico, contribuindo assim para o desenvolvimento, alargamento e socialização da área temática em investigação. No tocante aos autores em destaque da Figura 3, aflora-se Alfredo Sarlo Neto e José Elias Feres de Almeida, colocando-os como os acadêmicos mais centrais deste estudo (Rossoni \& Guarido Filho, 2007).

\subsection{IESs}

A Figura 4 evidencia as 51 IESs identificadas neste trabalho, colocando em foco as 17 mais produtivas. 
Figura 4: IESs

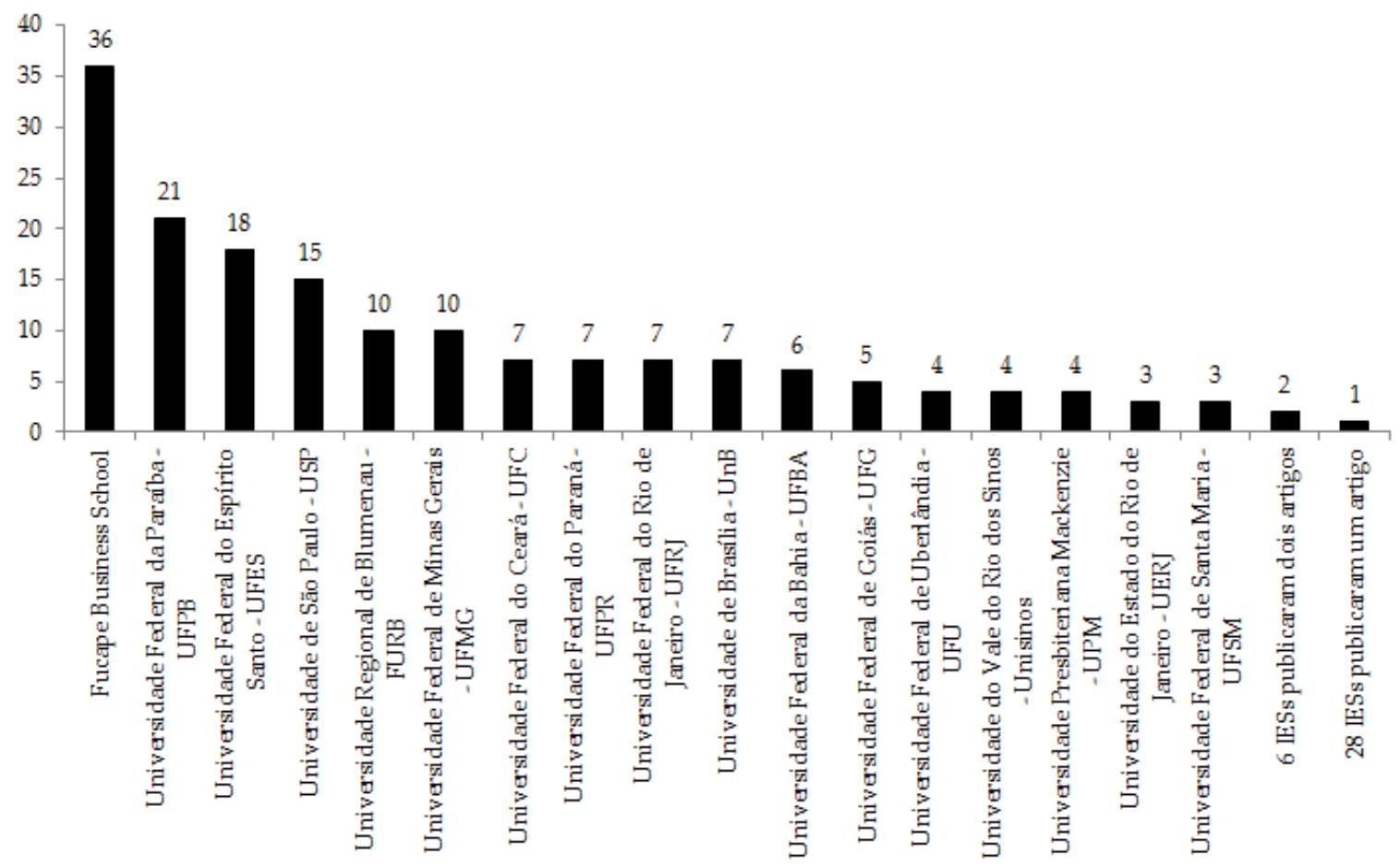

Fonte: Dados da pesquisa

A Fucape Business School é a IES mais profícua deste estudo, com 36 artigos publicados. A UFPB se destacou, ficando em segundo lugar, com 21 publicações. Em terceiro está a UFES com 18 trabalhos divulgados. A USP vem logo em seguida com 15 publicações. Com dez têm as IESs: FURB e UFMG. Já com sete surgem as instituições: UFC, UFPR, UFRJ e UnB. A UFBA aparece com seis papers. Com cinco vem a UFG. Já com quatro pesquisas, surgem as instituições: UFU, Unisinos e UPM. E com três têm as IESs: UERJ e UFSM. Estes achados vão ao encontro do estudo de Amaral et al. (2014). E de maneira similar, as investigações dos pesquisadores: Leal, Oliveira e Soluri (2003), Herling et al. (2015) e Ribeiro (2017) corroboram com os resultados desta pesquisa. Realça-se também, que as IESs em destaque, são predominantes da região Sudeste. Tal achado é confirmado no estudo de Leal, Almeida e Bortolon (2013).

Ainda cabe mencionar que seis instituições publicaram dois artigos; e que uma grande parte, ou seja, 28 IESs publicaram somente um estudo. Diante disso, percebe-se a grande quantidade de IESs que colaboram com a manifestação, difusão e socialização da área temática ora investigada. $\mathrm{O}$ que mostra que, o congresso usado como foco nesta investigação, se preocupa em abrir oportunidades da evidenciação e disseminação da informação e do conhecimento científico da área temática objeto de estudo, impactando a posteriori no campo do saber das finanças e consequentemente da área contábil.

\subsection{Rede social das IESs}

A Figura 5 visualiza a rede social das 51 IESs identificadas nesta investigação, enfatizando a centralidade de grau. 
Figura 5: Rede social das IESs (centralidade de grau)
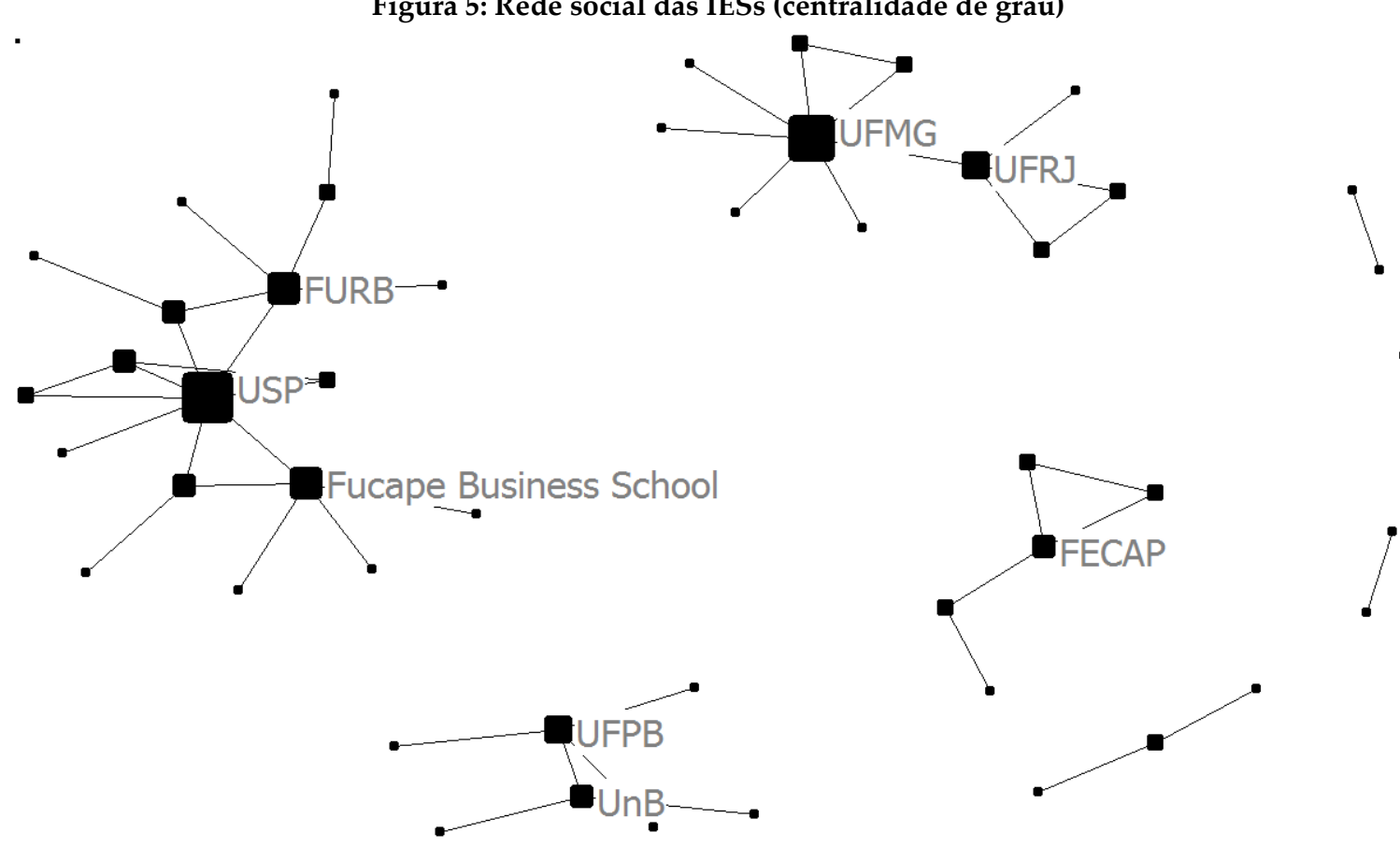

Fonte: Dados da pesquisa

As IESs: Fucape Business School, UFPB, USP, FURB, UFMG, UFRJ, UnB e FECAP se destacaram como sendo as mais centrais, no que tange ao degree. É interessante notar, que, destas oito, sete estão entre as mais profícuas. Mostrando que, estas instituições são as mais relevantes e importantes para a troca de informação e conhecimento, impactando na evolução de temas relacionados a área temática ora analisada. As instituições relacionadas nesta seção se fazem necessárias para difundir, disseminar e socializar a mencionada área temática.

Já a Figura 6, vislumbra a mesma rede social das IESs vistas na Figura 5, contudo, enfocando a centralidade de intermediação.

Figura 6: Rede social das IESs (centralidade de intermediação)
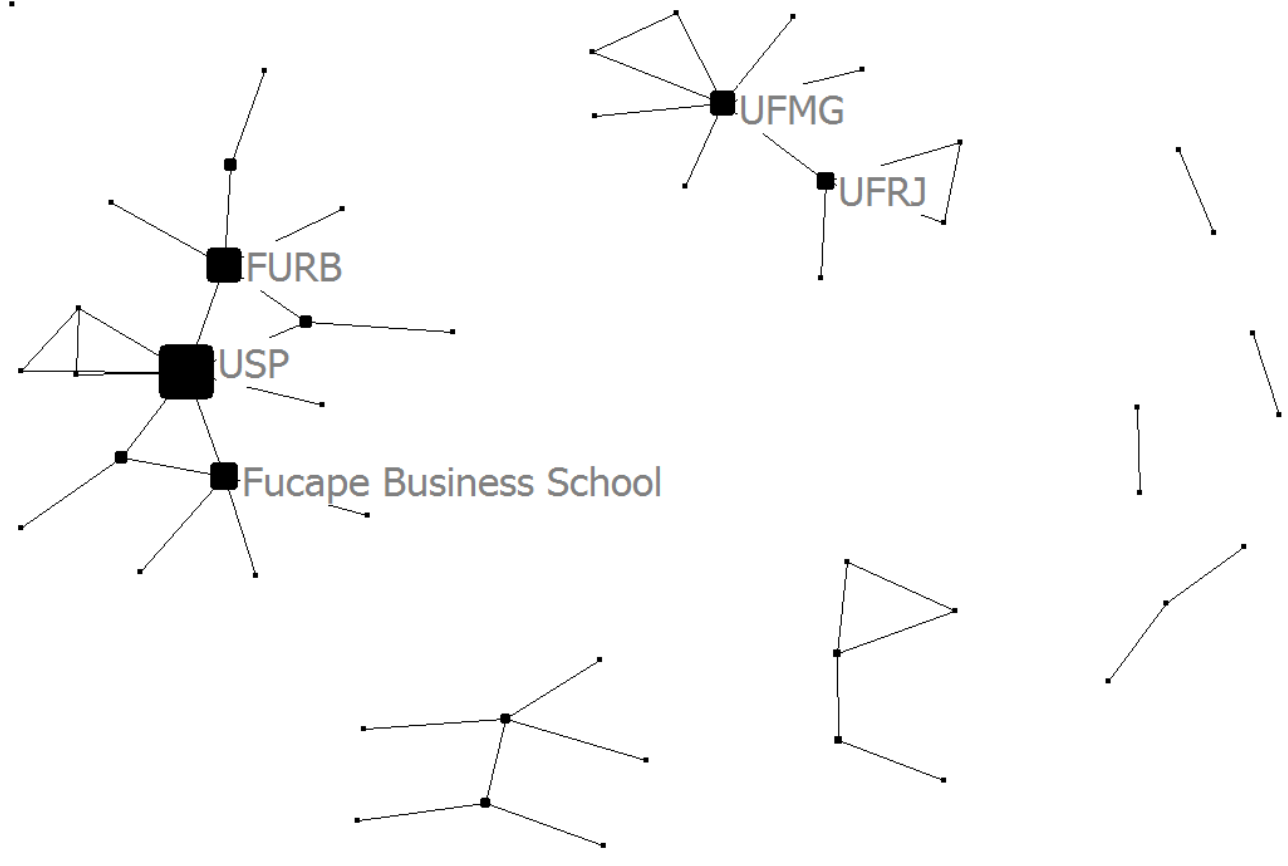

Fonte: Dados da pesquisa 
Das oito IESs realçadas na Figura 5, cinco surgem como as mais centrais, no que se refere ao betweenness, são elas: Fucape Business School, USP, FURB, UFMG e UFRJ. Diante deste achado, é viável afirmar que, estas instituições são as mais relevantes e importantes para o aperfeiçoamento, evidenciação e alargamento da área temática em investigação, em decorrência das respectivas envergaduras, estas instituições, além de ficarem em destaque como as mais centrais desta pesquisa, também surgem e estão entre as mais produtivas.

Neste panorama, é salutar dizer que, apesar destas instituições serem essenciais e preponderantes para o crescimento da área temática mercados financeiro, de crédito e de capitais e de temas relacionados a ela, outras IESs, poderão posteriormente surgir ou amadurecem ou se legitimarem ao longo dos anos, criando ou alargando o núcleo de instituições. Caso isso venha a ocorrer, tanto o congresso em evidencia neste estudo, quanto, a área temática divulgada por este evento científico e investigada neste estudo, poderá ser impactada positivamente, ampliando assim as nuance e o bojo das pesquisas, direcionando assim, o aparecimento, crescimento, maturação e/ou legitimidade de temas vinculados a esta área temática, influenciando em seu afloramento na literatura científica brasileira.

\subsection{Temas abordados}

A Tabela 1 evidencia os 57 temas identificados neste estudo, colocando em foco, os dez mais publicados. 
Tabela 1 - Temas pesquisados

\begin{tabular}{|c|c|c|c|c|c|c|c|c|c|c|c|c|}
\hline Temas/Anos & 07 & 08 & 09 & 10 & 11 & 12 & 13 & 14 & 15 & 16 & Total & $\%$ \\
\hline Governança corporativa & & & 3 & 2 & 3 & 5 & 1 & & 7 & 4 & 25 & $16,03 \%$ \\
\hline Investimento & 2 & & 1 & 1 & 3 & 2 & 1 & 1 & 1 & 1 & 13 & $8,33 \%$ \\
\hline Informações contábeis & & & 1 & 1 & 2 & 2 & 1 & 1 & & & 8 & $5,13 \%$ \\
\hline Gerenciamento de resultados & 1 & 1 & 1 & & & & & 1 & 2 & 1 & 7 & $4,49 \%$ \\
\hline Auditoria & & & & 1 & & 1 & 1 & 1 & 1 & 1 & 6 & $3,85 \%$ \\
\hline Estrutura de capital & & & & 1 & & & 1 & 1 & 1 & 2 & 6 & $3,85 \%$ \\
\hline Gestão de risco & 1 & & 1 & 1 & & 1 & 1 & 1 & & & 6 & $3,85 \%$ \\
\hline Mercado corporativo & & & 1 & & 1 & & 1 & 1 & & 2 & 6 & $3,85 \%$ \\
\hline Retorno das ações & & & & 1 & & 1 & & 2 & 1 & 1 & 6 & $3,85 \%$ \\
\hline Avaliação de empresas & & & 1 & 2 & & 1 & 1 & & & & 5 & $3,21 \%$ \\
\hline Ativos intangíveis & 2 & & & & & & & & 2 & & 4 & $2,56 \%$ \\
\hline Dividendos & & & & & 1 & 1 & & & & 2 & 4 & $2,56 \%$ \\
\hline Analista financeiro & 1 & & & & & & & & 1 & 1 & 3 & $1,92 \%$ \\
\hline Capital Asset Pricing Model (CAPM) & & 1 & & & 1 & & & 1 & & & 3 & $1,92 \%$ \\
\hline Custo de capital & & & & & & & & 1 & & 2 & 3 & $1,92 \%$ \\
\hline Assimetria informacional & & & & & & & 1 & & & 1 & 2 & $1,28 \%$ \\
\hline Conservadorismo contábil & & & & 1 & & 1 & & & & & 2 & $1,28 \%$ \\
\hline Contabilidade internacional & & & & & 1 & & & & & 1 & 2 & $1,28 \%$ \\
\hline Índices financeiros & & & & & & & 1 & 1 & & & 2 & $1,28 \%$ \\
\hline Pesquisa e desenvolvimento (P\&D) & & & 1 & 1 & & & & & & & 2 & $1,28 \%$ \\
\hline Preço das ações & & & 1 & 1 & & & & & & & 2 & $1,28 \%$ \\
\hline Recompra de ações & & & 1 & & & & & & & 1 & 2 & $1,28 \%$ \\
\hline Valor justo & & & & & & & & 2 & & & 2 & $1,28 \%$ \\
\hline Value relevance & & & & & & & 1 & 1 & & & 2 & $1,28 \%$ \\
\hline Board Interlocking & & & & & & & & 1 & & & 1 & $0,64 \%$ \\
\hline BRICS & & & & & & & & 1 & & & 1 & $0,64 \%$ \\
\hline Capital de giro & & & & & & & 1 & & & & 1 & $0,64 \%$ \\
\hline Coeficiente de resposta de ganhos & & & & & & & & & 1 & & 1 & $0,64 \%$ \\
\hline Controle Interno & & & & & & & & & & 1 & 1 & $0,64 \%$ \\
\hline Debêntures & & 1 & & & & & & & & & 1 & $0,64 \%$ \\
\hline Desempenho financeiro & & & & 1 & & & & & & & 1 & $0,64 \%$ \\
\hline Desempenho operacional & & & & & & & & 1 & & & 1 & $0,64 \%$ \\
\hline Educação financeira & & & & & & & 1 & & & & 1 & $0,64 \%$ \\
\hline Empréstimo & & & & & & & 1 & & & & 1 & $0,64 \%$ \\
\hline Estrutura da dívida & & & & & & & & & & 1 & 1 & $0,64 \%$ \\
\hline Finanças comportamentais & & 1 & & & & & & & & & 1 & $0,64 \%$ \\
\hline Folga Financeira & & & & & & & & & & 1 & 1 & $0,64 \%$ \\
\hline Fundos de pensão & & & & & & & & & 1 & & 1 & $0,64 \%$ \\
\hline Fusões e aquisições & & 1 & & & & & & & & & 1 & $0,64 \%$ \\
\hline Gestão ambiental & & & & 1 & & & & & & & 1 & $0,64 \%$ \\
\hline Hedge & & & & & & & 1 & & & & 1 & $0,64 \%$ \\
\hline Impairment loss reversal & & & & & & & & & 1 & & 1 & $0,64 \%$ \\
\hline Macroeconômia & & & & & 1 & & & & & & 1 & $0,64 \%$ \\
\hline Mercados emergentes & & & & & & & 1 & & & & 1 & $0,64 \%$ \\
\hline Modelo de Ohlson & & & & & & & 1 & & & & 1 & $0,64 \%$ \\
\hline
\end{tabular}




\begin{tabular}{|c|c|c|c|c|c|c|c|c|c|c|c|c|}
\hline Modelo DuPont & & & & & 1 & & & & & & 1 & $0,64 \%$ \\
\hline Negócio e desempenho & & & & 1 & & & & & & & 1 & $0,64 \%$ \\
\hline Ofertas subsequentes de ações (SEO) & & & & & & & & & 1 & & 1 & $0,64 \%$ \\
\hline Política de financiamento & & & & 1 & & & & & & & 1 & $0,64 \%$ \\
\hline Política financeira & & & & & & & & & 1 & & 1 & $0,64 \%$ \\
\hline Rentabilidade financeira & 1 & & & & & & & & & & 1 & $0,64 \%$ \\
\hline Resultado líquido & & & & & & & & & & 1 & 1 & $0,64 \%$ \\
\hline Risco operacional & & & & & 1 & & & & & & 1 & $0,64 \%$ \\
\hline Opções de ações & & & & & & & & 1 & & & 1 & $0,64 \%$ \\
\hline Sustentabilidade empresarial & & & & 1 & & & & & & & 1 & $0,64 \%$ \\
\hline Valor da Firma & & 1 & & & & & & & & & 1 & $0,64 \%$ \\
\hline Valor das ações & & & & & & & & 1 & & & 1 & $0,64 \%$ \\
\hline Total & 8 & 6 & 12 & 18 & 15 & 15 & 17 & 20 & 21 & 24 & 156 & $100,00 \%$ \\
\hline
\end{tabular}

Fonte: Dados da pesquisa

Governança corporativa foi o tema mais publicado neste estudo com 25 divulgações. Este resultado deve-se muito ao fato de que o citado tema ser um conjunto de regras, práticas e instituições que determinam como os gestores agem no melhor interesse dos stakeholders da organização (Leal \& Saito, 2003) e por ser um tema multidisciplinar, legitimado, que se encontra em um grau alto de envergadura, sofisticação, rigidez e coerência em sua estrutura intelectual (Durisin \& Puzone, 2009). Tal fato pode ser visto por meio de outras pesquisas que mostram a proeminência e importância do tema governança corporativa na produção acadêmica nacional (Ribeiro et al., 2012, Ribeiro, 2014; Ribeiro, Costa \& Ferreira, 2015). A pesquisa de Faria, Andrade e Gonçalves (2015) corrobora com tais achados, ao evidenciar que o tema governança corporativa se destaca na área de finanças.

Em seguida surge o tema Investimento com 13 publicações. Com oito investigações aparece a temática Informações contábeis. Seu destaque vem por sua importância, pois, mediante ela, é desenvolvida as relações entre os vários atores econômicos (Szüster, Szüster \& Szüster, 2005), sendo relevantes e influenciando diretamente o mercado financeiro (Titman, 2013) e de capitais no Brasil (Gonçalves, Batista, Macedo \& Marques, 2014).

O tema Gerenciamento de resultados também ficou em realce nesta investigação, pois foi evidenciado em sete artigos. Tal resultado reflete a importância e o crescimento deste tema na literatura acadêmica nacional (Seidler \& Decourt, 2014). Ainda segundo os autores Seidler \& Decourt (2014) os estudos sobre gerenciamento de resultados estão relacionados com a governança corporativa e a auditoria; e que os pesquisadores nacionais buscam alargar o horizonte de investigações sobre o referido tema.

As temáticas: Auditoria, Estrutura de capital, Gestão de risco, Mercado corporativo e Retorno das ações foram publicados cada uma, seis vezes. Versa-se que a auditoria é uma temática importante e peça-chave no mercado financeiro, especialmente no que diz respeito as boas práticas de governança corporativa (Zaman, Hudaib \& Haniffa, 2011). E, no âmbito da governança corporativa tem-se o Comitê de Auditoria como um mecanismo (Pucheta-Martínez \& García-Meca, 2014) que fornece um canal de entendimento entre o Conselho de Administração e os auditores (Furuta \& Santos, 2010).

Salienta-se também o assunto Estrutura de capital, que, como já foi visto, ficou também em evidencia neste estudo. Tal fato, é em decorrência de que a estrutura de capital é um tema bastante debatido na área de finanças (Brito, Corrar \& Batistella, 2007), no mercado corporativo (Corrêa, Silva, Pinheiro \& Melo, 2015) e, sobretudo, no mercado de capitais (Bastos, Nakamura \& Basso, 2009). Como contemplado antes, o tema mercado corporativo também ficou em realce nesta investigação. 
O tema Gestão de risco, como manifestado anteriormente, aparece com seis publicações. Isto posto, remete a sua relevância e crescimento na literatura acadêmica nacional, por meio da quantidade e heterogeneidade de temáticas relacionadas a ele, dentre estas, o tema mercado de capitais (Ribeiro, 2017). Outro assunto que apareceu com seis divulgações foi o Retorno das ações. E com cinco artigos publicados aparece o tema Avaliação de empresas. Ainda cabe mencionar que 35 temáticas foram divulgadas de quatro a duas vezes; e 33 temas foram publicados somente uma vez cada.

Diante disso, cabe dizer que, estes temas que foram publicados em menos quantidade na área temática mercados financeiro, de crédito e de capitais à luz do congresso AnpCONT, é uma oportunidade do surgimento de novos estudos, focando justamente estes assuntos ainda embrionários no que tange a área temática objeto de investigação. Estas temáticas, que neste momento, são incipientes, neste estudo, podem vir a se desenvolver e posteriormente evoluir, mediante as pesquisas científicas, impactando de maneira direta no crescimento e alargamento, como dito antes, da área temática ora investigado.

\section{CONSIDERAÇÕES FINAIS}

O objetivo deste estudo foi investigar o perfil e as características da produção científica dos artigos divulgados na AnpCONT na área temática Mercados Financeiro, de Crédito e de Capitais de 2007 a 2016. Para isso, utilizaram-se as técnicas de análise bibliométrica e de rede social nos 156 artigos identificados nesta investigação.

De maneira geral, este trabalho evidenciou dados e informações sobre os 10 anos de publicação de artigos vinculados a área temática Mercados financeiro, de crédito e de capitais à luz do congresso AnpCONT. Este bojo de informações contemplou o comportamento e as características das publicações sobre a área temática em investigação, trazendo dados contemporâneos, mediante indicadores bibliométricos e sociométricos, abarcando os atores que compõem os artigos, ou seja, os autores e as IESs que são oriundos.

Neste fato, observou-se uma predominância de publicações em parceria, sendo que se destacaram 13 pesquisadores por suas respectivas proficuidades, em especial Alfredo Sarlo Neto, Bruno Funchal e Márcio André Veras Machado. Em relação as redes de coautoria, ambas, isto é, a de centralidade de grau e de intermediação, possuem nível elevado de centralidade, baixa densidade e alta dispersão, impactando com isso em um possível, pelo menos neste instante, no alargamento, robusto e difusão da área temática objeto de estudo e seus temas dela nativos.

No contexto das instituições, realçam-se 17, contudo, colocam-se em maior evidencia as IESs: Fucape Business School, UFPB, UFES e USP. Sendo que destas, a Fucape Business School e a USP, se destacam além da produtividade, estão entre as instituições com maior centralidade de grau e de intermediação. E como ocorrerá, na rede de coautoria, foi visto uma baixa densidade de rede das IESs, influenciando com isso em sua dispersão e, em uma possível maior conexão entre os autores, impactando, pelo menos neste momento, na diversidade, maturidade e/ou legitimidade de temas relacionados a área temática em investigação.

No que tange aos temas, dos 57 identificados nos 156 artigos publicados, 10 tiveram maior realce, em especial o assunto governança corporativa, que vem se destacando no mercado financeiro (Amaral, Iquiapaza, Tomaz \& Bertucci, 2009) por sua abrangência no meio empresarial (Silva, 2004), impactando com isso, em seu forte debate, por meio de divulgações, na literatura acadêmica nacional (Colombo \& Galli, 2012).

Este estudo contribuiu para elencar dados e informações sobre a área temática Mercados financeiro, de crédito e de capitais, ajudando a entender, compreender, e coloca-la em um grau de juízo e abrangência, sobretudo para os autores iniciantes ou aqueles que pretendem ingressar na 
pesquisa. Os indicadores bibliométricos e sociométricos vislumbrados neste texto, procuraram evidenciar o perfil e as características da produção acadêmica da referida área temática, criando valor científico, e possibilitando um conhecimento contemporâneo deste campo do saber, impactando, de maneira direta nas áreas macro de finanças e de contabilidade.

Este estudo limitou-se na investigação das publicações da temática mercados financeiro, de crédito e de capitais da AnpCONT, entretanto, ressalta-se que foi conseguido responder à questão de pesquisa e alcançar o objetivo. Sugere-se dilatar tal estudo, fazendo uma comparação do perfil e das características da área temática investigada em outros eventos científicos da área contábil. Outra sugestão é trabalhar com os periódicos científicos nacionais Qualis Capes da área contábil e/ou afins, buscando saber como está o perfil e as características da área temática objeto de análise divulgada nestes meios de comunicação.

\section{REFERÊNCIAS}

Albuquerque Filho, J. B., \& Machado-da-Silva, C. L. (2009). Organizational practices and relationship structure in the field of metropolitan development. Revista de Administração Contemporânea, 13(4), 626-646.

Amaral, H. F., Iquiapaza, R. A., Tomaz, W. P., \& Bertucci, L. A. (2009). Governança corporativa e divulgação de relatórios financeiros anuais. Revista Contabilidade Vista \& Revista, 19(1), 61-82.

Almeida, M. A., Santos, J. D., Ferreira, L. D. M., \& Torres, F. J. V. (2010). Evolução da qualidade das práticas de governança corporativa: um estudo das empresas brasileiras de capital aberto não listadas em bolsa. Revista de Administração Contemporânea, 14(5), 907-924.

Amaral, M. R. do, Santana, C. M., Sales, I. C. H., e Araujo Neto, L. M. de. (2014). Perfil dos autores na produção científica em mercado financeiro de crédito e de capitais nos congressos USP de Controladoria e Contabilidade e congresso Anpcont. Revista Evidenciação Contábil \& Finanças, 2(2), 55-68.

AnpCONT - Associação Nacional de Programas de Pós-Graduação em Ciências Contábeis. (2017). Áreas temáticas. Recuperado em: < http://congressos.anpcont.org.br/>.

Anzilago, M., \& Melo, F. J. de. (2016). Networking nas relações institucionais: uma análise no congresso Anpcont entre o período de 2013 a 2015. Interfaces Científicas - Humanas e Sociais, 5(2), $97-112$.

Arboit, A. E., \& Bufrem, L. S. (2011). Produção de trabalhos científicos em eventos nacionais da área de ciência da informação. TransInformação, 23(3), 207-217.

Bastos, D. D., Nakamura, W. T., \& Basso, L. F. C. (2009). Determinantes da estrutura de capital das companhias abertas na América Latina: um estudo empírico considerando fatores macroeconômicos e institucionais. Revista de Administração Mackenzie, 10(6), 47-77.

Brito, G. A. S., Corrar, L. J., \& Batistella, F. D. (2007). Fatores determinantes da estrutura de capital das maiores empresas que atuam no Brasil. Revista Contabilidade E Finanças, 18(43), 9-19.

Caldas, M. P., \& Tinoco, T. (2004). Research on human resources management in the 90's: a bibliometric study. Revista de Administração de Empresas, 44(3), 100-114.

Cardoso, R. L., Mendonça Neto, O. R. de, Riccio, E. L., \& Sakata, M. C. G. (2005). Pesquisa científica em contabilidade entre 1990 e 2003. Revista de Administração de Empresas, 45(2), 34-45.

Catapan, A., Scherer, L. M., e Espejo, M. dos S. B. (2010). O efeito das informações contábeis no mercado de capitais: um estudo bibliométrico no período de 2000 a 2009. Revista de Contabilidade e Controladoria, 2(6), 47-60.

Chaddad, F. R., \& Lazzarini, S. G. (2003). Relações contratuais de crédito agrícola e o papel dos agentes financeiros privados: teoria e evidências dos EUA. Revista de Economia e Sociologia Rural, 41(3), 29-52. 
Colombo, J. A., \& Galli, O. C. (2012). Governança corporativa no Brasil: Níveis de governança e rendimentos anormais. Revista de Gestão dos Países de Língua Portuguesa, 11(2-3), 117-128.

Cordeiro, R. A., Sanches, P. L. B., Cavalcante, K. de O., Peixoto, A. F., \& Leite, J. C. de L. (2014). Pesquisa quantitativa em finanças: uma análise das técnicas estatísticas utilizadas por artigos científicos publicados em periódicos qualificados no triênio 2007 a 2009. Revista de Administração da UFSM, 7(1), 117-134.

Corrêa, E. D. L., Silva, W. A. C., Pinheiro, J. L., \& Melo, A. A. D. O. (2015). Estrutura de propriedade e criação de valor em companhias brasileiras. Tourism $\mathcal{E}$ Management Studies, 11(2), 130-137.

Cosenza, J. P., Paula, M. M. de, Laurencel, L. da C., \& Barreto, P. S. (2016). Análise das características e similaridades presentes na produção científica dos congressos ANPCONT 2007-2014. Revista Contemporânea de Contabilidade, 13(28), 19-56.

Crepaldi, A. F., Ferreira, F. F., \& Rodrigues, J. de S. (2012). Gestão \& Produção, 19(4), 793-809.

Cruz, A. P. C. da, Espejo, M. M. dos S. B., Costa, F., \& Almeida, L. B. de. (2011). Perfil das redes de cooperação científica: Congresso USP de Controladoria e Contabilidade - 2001 a 2009. Revista Contabilidade \& Finanças, 22(55), 64-87.

CVM - Comissão de Valores Mobiliários (2017). Mercado de capitais. Recuperado em: < http://www.cvm.gov.br/>.

Dallabona, L. F., Utzig, M. J. S., Moura, G. D. de, Zonatto, V., \& Ribeiro, M. J. (2011). Retrospectiva dos quatro anos de Anpcont: análise dos aspectos metodológicos e perfil dos congressistas. Advances in Scientific and Applied Accounting. 4(3), 406-432.

Diehl, C. A., Macagnan, C. B., Zanini, F. A. M., \& Wickboldt, L. A. (2010). Metodologias em artigos de finanças sobre dividendos nos periódicos brasileiros Qualis/Capes a partir de B2. Revista Pensamento Contemporâneo em Administração, 4(2), 18-35.

Dionne, G. (2013). Risk management: history, definition, and critique. Risk Management and Insurance Review, 16(2), 147-166.

Durisin, B., \& Puzone, F. (2009). Maturation of corporate governance research, 1993-2007: an assessment. Corporate Governance: An International Review, 17(3), 266-291.

Faria, E. R. de, Andrade, L. P. de, \& Gonçalves, M. A. (2015). Metodologias e temas pesquisados em finanças: uma análise bibliométrica nos principais periódicos do Brasil. Revista Administração em Diálogo, 17(3), 172-191.

Ferreira, M. P., \& Falaster, C. (2016). Uma análise comparativa dos fatores de rejeição nos periódicos de diferentes estratos de administração. Revista de Administração Contemporânea, 20(4), 412433.

Ferri, M. da S., \& Soares, R. O. (2009). Investidores institucionais e o foco no curto prazo: um estudo nas empresas negociadas na Bovespa. Revista Contabilidade Vista \& Revista, 20(4), 15-30.

Fialho, J. M. R. (2014). Análise de redes sociais: princípios, linguagem e estratégias de ação na gestão do conhecimento. Perspectivas em Gestão \& Conhecimento, 4(Número Especial), 9-26.

Fonseca, R., \& Utrero, N. (2017). Financial markets and firm size: The role of employment protection laws and barriers to entrepreneurship. Applied Economics, 49(26), 2515-2531.

Francisco, E. de R. (2011). RAE-eletrônica: exploração do acervo à luz da bibliometria, geoanálise e redes sociais. Revista de Administração de Empresas, 51(3), 280-306.

Furuta, F., \& Santos, A. dos. (2010). Comitê de Auditoria versus Conselho Fiscal adaptado: a visão dos analistas de mercado e dos executivos das empresas que possuem ADRs. Revista Contabilidade $\mathcal{E}$ Finanças, 21(53), 1-23.

Gonçalves, J. C., Batista, B. L. L., Macedo, M. A. da S., \& Marques, J. A. V. da C. (2014). Análise do impacto do processo de convergência às normas internacionais de contabilidade no Brasil: um estudo com base na relevância da informação contábil. Revista Universo Contábil, 10(3), 25-43. 
Gonçalves, T. A., Lima, N. C., Oliveira, S., Oliveira, M., \& Queiroz, J. V. (2012). Corporate governance in financial strategy of companies listed in Bovespa. International Journal of Business and Commerce, 2(12), 24-39.

Guedes, V. L. da S., \& Santos, M. J. V. da C. (2013). Recorrência de nominalizaçôes deverbais em resumos de cartas científicas em língua portuguesa e a indexaçâo temática. Lingüística, 29(1), 37-57.

Herling, L. H. D., Moritz, G. de O., Lima, M. V. A. de, \& Pereira, M. F. (2014). Análise da produção científica brasileira na área de finanças: panorama do Qualis A. Revista de Administração FACES, 13(4), 76-89.

Herling, L. H. D., Moritz, G. de O., Soares, T. C., \& Lima, M. V. A. de. (2015). Produção científica em finanças: mapeamento das publicações em periódicos Qualis A no Brasil. Revista de Ciências da Administração, 17(41), 51-64.

Kimura, H. (2003). Aspectos comportamentais associados às reações do mercado de capitais. RAEeletrônica, 2(1), 1-14.

Krugman, P. (2010). A crise de 2008 e a economia da depressão. Revista de Economia Política, 30(1), 180-182.

Leal, R. P. C., Almeida, V. de S. e, \& Bortolon, P. M. (2013). Produção científica brasileira em finanças no período 2000-2010. Revista de Administração de Empresas, 53(1), 046-055.

Leal, R. P. C., Oliveira, J. de, e Soluri, A. F. Perfil da pesquisa em finanças no brasil. Revista de Administração de Empresas, 43(1), 91-104.

Leal, R. P. C., \& Saito, R. Finanças corporativas no Brasil. Revista de Administração de Empresas, 2(2), $1-15$.

Leite Filho, G. A., \& Siqueira, R. L. (2007). Revista Contabilidade \& Finanças USP: uma análise bibliométrica de 1999 a 2006. Revista de Informação Contábil, 1(2), 102-119.

Malacrida, M. J. C., \& Yamamoto, M. M. (2006). Governança corporativa: nível de evidenciação das informações e sua relação com a volatilidade das ações do Ibovespa. Revista Contabilidade $\mathcal{E}$ Finanças, 17(SPE), 65-79.

Marques, F. C. R. (2010). Maximização de Lucros em Investimentos: uma abordagem a partir do MACD com o emprego de algoritmos genéticos e lógica fuzzy. Dissertação (Mestrado em Modelagem Matemáticae Computacional). CEFET, Belo Horizonte, 2010, 85 pg.

Martins, H. C., \& Rodrigues, S. B. (2005). Atributos e papéis dos conselhos de administração das empresas brasileiras. Revista de Administração de Empresas, 45(SPE), 23-35.

Matsuda, P. M., \& Donadone, J. C. (2015). A mudança da carreira dos dirigentes após o processo de privatização: estudo de caso no setor elétrico paulista. Gestão \& Produção, 22(2), 419-430.

Mello, C. M. de, Crubellate, J. M., \& Rossoni, L. (2010). Dinâmica de relacionamento e prováveis respostas estratégicas de programas brasileiros de pós-graduação em administração à avaliação da capes: proposições institucionais a partir da análise de redes de co-autorias. Revista de Administração Contemporânea, 14(3), 434-457.

Pimenta, A., \& Fama, R. (2014). Behavioral finance: a bibliometric mapping of academic publications in USA since 1993. Recuperado em: <https://ssrn.com/abstract=2406763 or http://dx.doi.org/10.2139/ssrn.2406763>.

Pucheta-Martínez, M. C., \& García-Meca, E. (2014). Institutional investors on boards and audit committees and their effects on financial reporting quality. Corporate Governance: An International Review, 22(4), 347-363.

Régis, H. P., Bastos, A. V. B., \& Dias, S. M. R. C. (2007). Redes sociais informais: análise das redes de amizade, de informação e de confiança em incubadoras de base tecnológica no Recife. Revista Psicologia Organizações e Trabalho, 7(1), 31-56. 
Ribeiro, H. C. M. (2014). Corporate governance versus corporate governance: an international review: uma análise comparativa da produção acadêmica do tema governança corporativa. Revista Contemporânea de Contabilidade, 11(23), 95-116.

Ribeiro, H. C. M., Costa, B. K., \& Ferreira, M. P. (2015). Governança corporativa nos esportes: análise dos últimos 23 anos de produção acadêmica em periódicos internacionais. Revista de Administração e Contabilidade da Unisinos, 12(2), 135-154.

Ribeiro, H. C. M., Junior, C. M., de Souza, M. T. S., de Abreu Campanário, M., \& Corrêa, R. (2012). Governança corporativa: um estudo bibliométrico da produção científica das dissertações e teses brasileiras. Contabilidade, Gestão e Governança, 15(3), 52-70.

Ribeiro, H. C. M. (2015). Particularidades da produção acadêmica publicada na Revista de Administração e Contabilidade da Unisinos no período de 2004 a 2014. Revista Contabilidade Vista e Revista, 26(3), 80-105.

Ribeiro, H. C. M. (2017). Produção acadêmica dos artigos publicados em revistas científicas nacionais disponibilizadas na base Atena sobre o tema gestão de riscos de 2000 a 2015. Revista Evidenciação Contábil \& Finanças, 5(1), 75-93.

Rocha, D. T. da, Cruz, J. A. W., Azevedo, M. B. de, Andrich, R. G., Tardelli, M., \& Abdalla, K. G. M. Z. (2014). Pensar Contábil, 16(60), 23-31.

Rossoni, L., \& Guarido Filho, R. (2007). Cooperação interinstitucional no campo dapesquisa em estratégia. Revista de Administração de Empresas, 47(4), 1-15.

Rossoni, L., Hocayen-da-Silva, A. J., \& Ferreira Júnior, I. (2008). Aspectos estruturais da cooperação entre pesquisadores no campo de administração pública e gestão social: análise das redes entre instituições no Brasil. Revista de Administração Pública, 42(6), 1041-1067.

Ruas, T. L., \& Pereira, L. (2014). Como construir indicadores de Ciência, Tecnologia e Inovação usando Web of Science, Derwent World Patent Index, Bibexcel e Pajek? Perspectivas em Ciência da Informação, 19(3), 52-81.

Santos, J. O. dos, \& Santos, J. A. R. dos. (2005). Mercado de capitais: racionalidade versus emoção. Revista Contabilidade E Finanças, 16(37), 103-110.

Seidler, J. C. O., \& Decourt, R. F. (2014). Gerenciamento de resultados: análise bibliométrica dos estudos científicos nacionais no período de 2006 a 2013. Registro Contábil, 5(2), 21-48.

Silva, A. D. (2004). Governança corporativa, valor, alavancagem e política de dividendos das empresas brasileiras. Revista de Administração da USP, 39(4), 348-361.

Szüster, N., Szüster, F. R., \& Szüster, F. (2005). Contabilidade: atuais desafios e alternativa para seu melhor desempenho. Revista Contabilidade \& Finanças, 16(38), 20-30.

Titman, S. (2013). Financial markets and investment externalities. The Journal of Finance, 68(4), 13071329.

Vieira, T. R. C., \& Pereira, A. N. (2009). Finanças comportamentais no brasil: um estudo bibliométrico (2001-2007). Revista de Gestão USP, 16(4), 45-59.

Zaman, M., Hudaib, M., \& Haniffa, R. (2011). Corporate governance quality, audit fees and NonAudit services fees. Journal of Business Finance \& Accounting, 38(1-2), 165-197. 